Artigo recebido em:

29.04.2016

Aprovado em:

22.07.2016

Juliana Motta, Jornalista formada pela Universidade Federal de Santa Maria, Mestre em Comunicação no Programa de Pós-graduação em Comunicação Midiática (UFSM) e integrante do Grupo de Pesquisa Estudos em Jornalismo na mesma instituição. ju.motta17@gmail.

com

Márcia Franz Amaral, jornalista formada pela Universidade

Federal de Santa

Maria, Mestre em Comunicação pela mesma instituição, Doutora em Comunicação e Informação pela Universidade Federal do Rio Grande do Sul com pós-doutorado pela Universitat Pompeo

Fabra (Barcelona - Espanha); é professora associada da Universidade Federal de Santa Maria e autora do livro Jornalismo Popular (Editora Contexto). marciafranz.amaral@ gmail.com

Estudos em Jornalismo e Mídia Vol. 13 No 1

Janeiro a Junho de 2016, ISSNe 1984-6924

\section{Os testemunhos na cobertura jornalística do caso Kiss: transbordamento emocional e provas de verdade}

\author{
Juliana Motta \\ Márcia Franz Amaral
}

\section{Resumo}

O artigo analisa a participação dos testemunhos na cobertura jornalística de televisão ao vivo do incêndio da boate Kiss, em 2013. Buscamos compreender os papéis desempenhados pelas fontes testemunhais na cobertura e discutir como o efeito patêmico presente nos testemunhos colabora não só para a visada de captação, como também para a de informação. Para isso, analisamos as entradas ao vivo veiculadas pela Rede Globo de Televisão e sua afiliada RBS TV, nos dias 27, 28 e 29 de janeiro de 2013, a partir da sistematização de Charaudeau (2010) sobre os meios discursivos de provar a verdade (designação, reconstituição e elucidação) e de conferir emoção (efeito patêmico). Verificamos o predomínio das provas de verdade $(66,6 \%)$, porém concluímos que dado ao contexto trágico do acontecimento, o efeito patêmico está presente até mesmo nos enunciados da visada da informação. Da mesma forma, observamos que as sequências classificadas como patêmicas também apresentam provas de verdade.

\section{Palavra-chave:}

cobertura jornalística de tragédias, testemunho, Boate Kiss

\section{Abstract}

This article analyzes the participation of witnesses in the live television news coverage of Kiss Nightclub fire, in 2013. The roles played by witness sources on coverage were tried to be comprehended and discussions on how the pathos effect, which is present in the manifestation of the testimonies contribute, not only to the target capture, but also for information. For this, the live entries broadcast by Globo Television Network and its RBS TV affiliate were analyzed, on January 27, 28 and 29, 2013, from the systematization of Charaudeau (2010) on the discursive means to present real evidence (designation, reconstruction and elucidation) and to give emotion (pathos effect). There was a predominance of real evidence $(66,6 \%)$, however, it is concluded that on the context of the tragic event, the pathos effect is present even in the statements of the target information. Likewise, it was observed that the sequences classified as pathos effect also present real evidence.

\section{Keywords:}

media coverage on tragedies, testimony, Kiss Nightclub 
${ }^{1}$ O número total de mortos foi de 242.

${ }^{2}$ Classificamos as fontes a partir da sistematização de Amaral (2013a, p.183) que considera "fontes autorizadas ou oficiais as pessoas com função de representação institucional ou organizacional. Os experts são fontes que dispõem de um conjunto de conhecimentos especializados e competências específicas e são convocados para explicar o fato pela sua qualificação profissional. Já os testemunhos têm visibilidade pelo relato

da sua experimentação, pois presenciaram o fato, participaram diretamente da sua causa ou sofreram as consequências dele. A partir disso, entendemos como fontes autorizadas/ oficiais: policiais militares, policiais civis, promotores de justiça, representantes de diretórios acadêmicos, secretários municipais e estaduais, prefeito, governador e ministros; como fontes especialistas: integrantes

do Corpo de Bombeiros

e da Defesa Civil, ana-

listas de áreas específicas (segurança, risco, emergência, incêndio), médicose advogados; e como fontes testemunhais: sobreviventes, familiares das vítimas e dos sobreviventes, amigos das vítimas, professores, voluntários e moradores da cidade sensibilizados pela tragédia.
O vocalista da banda resolveu colocar (...) aquela coisa que não é permitida na torcida no estádio na mão e acendeu. E no momento que acendeu, começou a agitar e a pular, e ergueu demais o braço, e é baixinho o teto. E logo em seguida, pegou fogo no forro, na forração, no telhado (Programa Especial Tragédia em Santa Maria, 27/01/2013).

Eu achei que ia morrer. Não tinha o que fazer. O pessoal gritando, o fogo na frente. As pessoas pareciam animais, pisando. Eu fui sair, na hora em que eu consegui sair me pisaram no pescoço, no peito, nas costas, nas pernas (Jornal Nacional, 28/01/2013).

Estes são alguns dos muitos testemunhos veiculados durante a cobertura televisiva do incêndio da Boate Kiss, ocorrido em Santa Maria (RS), no dia 27 de janeiro de 2013. Os relatos de quem conseguiu escapar da casa noturna são dramáticos, porém não revelam somente o terror e o desespero vividos, mas também elementos mais pontuais que contribuem para a reconstituição dos acontecimentos daquela madrugada. Com mais de duas centenas de mortos, o caso teve repercussão mundial e mobilizou jornalistas de diferentes partes do mundo. Era preciso contar como e por que a festa organizada por universitários, com o objetivo de angariar recursos para a formatura, havia se transformado em uma das maiores tragédias do país. E foram, justamente, estes jovens sobreviventes que, ainda em meio à fumaça, aos resgates e às tentativas de reanimação das vítimas, apontaram os primeiros indícios do ocorrido na boate.

Utilizamos como aporte teórico-metodológico o conceito de contrato de comunicação, na perspectiva de Charaudeau (2010), e suas visadas de informação (fazer saber) e de captação (fazer sentir). A partir desse caso refletimos acerca da participação dos testemunhos na cobertura ao vivo de tragédias, mais especificamente a contribuição dos depoimentos patêmicos não só para a visada de captação, mas também para a de informação. Compreendemos que o jornalismo está em permanente tensão, pois precisa atender ao seu compromisso fundante de informar aos cidadãos e, ao mesmo tempo, captar a audiência por meio da emoção - o que segundo o autor, pode ameaçar a credibilidade do veículo. Os testemunhos participam ativamente deste conflito, já que a emoção é um traço marcante do depoimento resultante de uma situação extrema. Porém, na pesquisa não tratamos da emoção sentida pelo sujeito, mas sim da emoção relatada que, ao ser inserida no discurso, é denominada efeito patêmico. De acordo com os autores, o termo, baseado na noção de pathos de Aristóteles, significa um transbordamento emocional da ordem da enunciação midiática, expresso por meio de regras práticas e capazes de produzir sentimentos diversos no público (CHARAUDEAU, MAINGUENEAU, 2014).

Assentadas nesse aporte teórico, partimos para a análise do nosso corpus de pesquisa formado por 44 entradas ao vivo, veiculadas na Rede Globo de Televisão e na sua afiliada RBS TV (as primeiras emissoras de canal aberto do país a iniciarem a cobertura ao vivo da tragédia), nos dias 27, 28 e 29 janeiro de 2013. Justificamos o período de análise pelo entendimento de que as fontes testemunhais são mais convocadas nos primeiros dias de cobertura. Além disso, no quarto dia de transmissão, as participações em tempo real foram restritas aos repórteres, sem entrevistas de fontes.

A apreciação dos materiais foi orientada por um protocolo composto de itens como: nome do programa, endereço eletrônico, data da veiculação, duração da entrevista, tema da reportagem, contexto da entrevista, quantidade de fontes, a classificação de fontes ${ }^{2}$ (autorizada/oficial, especialista, testemunhal), o seu papel social e presença de outras fontes.

A transcrição do depoimento e a posterior identificação de traços de provas de verdade e de efeito patêmico foram realizadas apenas nas fontes teste- 
munhais, a partir da sistematização de Charaudeau (2014, p.49). O autor identifica três formas de provar a verdade do relato: a designação, que confere autenticidade ao que é mostrado e fornece provas de que o fato realmente ocorreu; a reconstituição, pela qual se busca atingir a verossimilhança dizendo como o fato deve ter acontecido; e a elucidação, que explica os fatos a partir de suas origens e motivos. Sobre a patemização, embora o autor a associe às estratégias de captação (fazer sentir), admite que o efeito também diz respeito aos efeitos de verdade (fazer saber), tendo em vista que sua ocorrência está atrelada ao princípio de referencialidade e veridicção do jornalismo. Assim, a pesquisa destinou esforços no estudo de como as declarações que se restringem aos relatos de emoção, ajudam também na ampliação do conhecimento sobre o fato. Parte dos resultados obtidos a partir desse aporte teórico-metodológico é o que será apresentado neste artigo.

Testemunhos no jornalismo: ícones de verdade e de marcação de realidade

A ligação do testemunho com a verdade, ou melhor, com a potencialidade de trazer à tona uma verdade advém da própria origem da palavra, que em latim pode ser identificada de duas maneiras: testis e superstes. A primeira refere-se ao uso judicial quando uma pessoa, considerada neutra, assume a posição de terceiro em relação a outras duas envolvidas em um litígio. Já o termo superstes identifica quem vivenciou determinado fato, sobreviveu à experiência e, por isso, pode ser testemunha (AGAMBEN, 2008, p.27).

Até hoje, essas duas possibilidades podem ser percebidas em diferentes áreas que estudam o testemunho. Em especial na literatura, esse tipo de depoimento passou a ter mais visibilidade a partir dos grandes acontecimentos trágicos do século XX. No período chamado de "era das catástrofes" (SELIGMANN-SILVA, 2003, p.8), dois eventos deram origem a perspectivas de estudo: os testemunhos de Shoah a partir dos sobreviventes do Holocausto e os testemonios das vítimas das ditaduras da América Latina.

Nos estudos de Shoah, a principal discussão é sobre a inexistência da testemunha autêntica, pois quem vivenciou a experiência até o final não sobreviveu para contar. Por isso, o Holocausto é considerado um "acontecimento sem testemunhas" (AGAMBEN, 2008, p.43). Nesse caso, os sobreviventes são considerados pseudotestemunhas que falam como porta-vozes dos mortos.

Esse mesmo caráter de resgate de uma vivência também está presente nos testemonios, entretanto, a tônica recai sobre o caráter de denúncia do relato das testemunhas (SELIGMANN-SILVA, 2003, p.32). O testemonio é visto como uma literatura de resistência que denuncia a exploração econômica e a repressão das minorias nas ditaduras latino-americanas das décadas de 1950 a 1970. Deste modo, como salienta Penna (2003, p.304), o testemonio tem o objetivo de contar a história sob outros pontos de vista até então silenciados: dos explorados e subalternos.

Embora afirme que o testemunho é fundamental quando não existe possibilidade de consulta a outras fontes, Sarlo (2005, p.163) lança dúvidas à atribuição de uma autenticidade inquestionável ao relato baseado na experiência. De acordo com a autora, após os dois eventos, criou-se um modelo de testemunho que é aplicado a qualquer situação. Assim, defende a necessidade de o testemunho também ser submetido ao rigor metodológico praticado com outras fontes.

Ricoeur (2007, p.172) argumenta que essa relação de suspeita e confiança se justifica por todo um processo de percepção da situação vivida e sua inserção na lembrança até chegar à narração que reconstitui os "traços do acontecimento". Porém, essa mesma experiência que suscita questionamentos por sua subje- 
tividade também colabora para a confiabilidade presumida, pois a autoridade da testemunha decorre diretamente da sua vivência e presença no local dos fatos em questão.

Trazendo a discussão para o campo jornalístico, Leal e Antunes (2015, p.4) entendem que o texto midiático é, por natureza, testemunhal. Porém, alertam a necessidade de se estabelecer uma diferença entre os testemunhos que serviram de base para os estudos iniciais e os midiáticos. No primeiro caso, tem-se depoimentos individuais (embora com aspirações de representação coletiva) provenientes de vivências em situações extremas; já no segundo, um texto planejado e construído no qual o aspecto testemunhal está mais ligado a fins estratégicos de autenticação dos relatos. Portanto, ainda que se considere a intenção de denúncia, resgate histórico e responsabilização dos culpados, pode-se compreender o testemunho dos sobreviventes, por vezes, como "desinteressado" e sem outro objetivo a não ser o de contar o que viveu. A mesma inferência não pode ser estabelecida no texto midiático, empreendido a partir de regras e procedimentos discursivos visando ao convencimento do público sobre a veracidade dos relatos.

À vista dessa construção estratégica, o testemunho evidencia-se como um recurso de marcação de realidade no qual o depoimento da pessoa envolvida na situação confere um efeito de verdade ao discurso. É justamente esse caráter de fidedignidade que faz o testemunho ser tão caro ao jornalismo, já que para atender à exigência de credibilidade do contrato de comunicação, é necessário provar ao público ser o seu relato verdadeiro. Nesse sentido, por estar ancorada em uma experiência vivida, a fala da testemunha instaura um "imaginário de verdade verdadeira” (CHARAUDEAU, 2010a, p.22), tornando o discurso credível. Dessa forma, acreditamos que uma das primeiras funções do testemunho no jornalismo é conferir o efeito de verdade ao discurso.
Além disso, o testemunho ainda contribui com o discurso jornalístico ao fornecer elementos que favorecem reconfiguração dos acontecimentos, principalmente em coberturas de tragédia, quando a apuração é dificultada pela desorganização provocada pelo fato e a escassez de fontes oficiais dispostas a fornecer informações à imprensa. Embora, nessas situações, os depoimentos sejam "um relato simultâneo ao acontecimento, com características efêmeras e fragmentadas e sem a pretensão de reconstituir a história como um todo" (AMARAL, 2013a, p.187), essa recomposição vai sendo concretizada a partir dos fragmentos de diferentes testemunhos.

Nessas situações, o testemunho também tem forte ligação com o sofrimento, principalmente quando o objetivo da convocação é ilustrar o drama vivido por sobreviventes e indivíduos afetados de alguma maneira pelo acontecimento (AMARAL, 2013b). Por ser decorrente de uma vivência de situação extrema, é esperado o forte apelo dramático do depoimento da fonte testemunhal. Porém, mais do que em virtude da própria natureza do acontecimento, essa perspectiva se sobressai porque é resultado de uma escolha jornalística. Durante a construção da reportagem, o profissional que apura, narra e organiza o discurso, também destina lugares de fala específicos para as fontes. Às oficiais/autorizadas e especialistas, cabem as explicações e análises contextualizadas; enquanto às testemunhais, falas mais subjetivas e pertencentes ao campo das sensações que devem expressar os aspectos vividos, sentidos, vistos ou ouvidos. Assim, o testemunho fica restrito ao tom "do urgente, do pungente, do desespero" (AMARAL, 2011, p.74). De outro modo, compreende-se que esses detalhes singulares advindos das testemunhas também se constituem em informações importantes para a construção do discurso jornalístico. Caso contrário, quem mais poderia ressaltar o aspecto humano inerente a uma cobertura de tragédia, senão as pes- 
soas que viveram esse acontecimento? Dessa forma, esse testemunho vai ao encontro de duas necessidades: da testemunha que, seguindo o modelo de Shoah, precisa contar o que sofreu seja com o intuito de desabafar, compartilhar a experiência ou buscar por justiça; e do jornalista, que necessita reconstituir o fato.

\section{Quem fala mais na cobertura? Um mapeamento da convocação das fontes}

Nas 44 entradas ao vivo que compõem o corpus, verificamos participação de 61 fontes jornalísticas, sendo 20 autorizadas/oficiais, 25 especialistas e 16 testemunhais. Observamos também a oscilação na convocação dessas fontes, principalmente, no primeiro dia de cobertura (domingo, 27/01/2013). A partir disso, chegamos à conclusão de que as testemunhais são priorizadas pelos jornalistas nas primeiras horas após o fato, quando é necessário entender, ainda em caráter preliminar, o que aconteceu.

Embora, de maneira geral, tenha ocorrido um equilíbrio na convocação de fontes $(33,3 \%$ de cada tipo) no domingo, verificamos uma significativa variação por turnos. Durante a manhã, por exemplo, $75 \%$ das fontes ouvidas foram testemunhais e $25 \%$ especialistas. Já no período da tarde, as testemunhas despencaram para um índice de $26,6 \%$, enquanto as autorizadas/oficiais emergiram para $46,6 \%$ e as especialistas mantiveram-se próximas do índice inicial (26,6\%). Os dados demonstram que, quando o período de caos e desestruturação do ambiente provocado pela tragédia (LOZANO ASCÊNCIO, 2004) é superado e algumas informações estabilizadas, as testemunhas perdem parte de seu prestígio, cedendo lugar às fontes autorizadas/oficiais e especialistas. Ainda é preciso levar em conta que, inicialmente, as autoridades evitam a exposição pública por estarem envolvidas com os trabalhos de investigação e resgate ou ainda por não possuírem informações confirmadas. Isto também contribui para a as- censão das testemunhas.

A variação das fontes também ocorre em função das demandas da cobertura que se modificam com o passar do tempo. No decorrer do domingo (27/01/2013), as testemunhas ascenderam em virtude da necessidade de apurar detalhes que ajudassem no esclarecimento dos fatos; já na segunda-feira (28/01/2013), as especialistas foram priorizadas (aumento de $33,3 \%$ para $53,5 \%$ ) visando a um aprofundamento das questões. Neste mesmo dia, tiveram queda nas convocações tanto as fontes autorizadas/oficiais (redução de $33,3 \%$ para 28,5\%) como as testemunhais (redução de $(33,3 \%$ para $17,8 \%)$. Por outro lado, na terça-feira (29/01/2013), com as atenções direcionadas para as responsabilizações pela tragédia, percebemos o crescimento das fontes autorizadas/oficiais (aumento de $28,5 \%$ para $41,6 \%$ ), a diminuição das especialistas (redução de 53,5\% para 25\%) e o crescimento das testemunhais (aumento de $17,8 \%$ para $33,3 \%)$. Sobre as testemunhas, ainda observamos que os depoimentos passaram a ter um caráter muito mais ilustrativo do que explicativo, tendo em vista as questões iniciais (como o fogo iniciou e como foi a saída da boate) já estarem parcialmente delineadas. Isto é, com o avanço das investigações e a alteração do enfoque da cobertura, há o retorno da lógica usual do jornalismo de priorizar as fontes cujo capital social está baseado na autoridade e no conhecimento (BOURDIEU, 1997).

\section{Há o retorno da lógica usual do jornalismo de priorizar as fontes}

Além disso, tendo como caraterísticas a visão parcial e restrita ao seu ângulo de observação, os testemunhos não têm ca- 
pacidade para fornecer informações técnicas ou que reconstituam o acontecimento como um todo. Após essa constatação, voltamos o olhar para o conteúdo desses depoimentos com o objetivo de traçar um panorama da participação das fontes testemunhais.

\subsubsection{Quem diz o quê? A formula- ção de uma tipologia do testemunho}

Para desenvolver uma tipologia do testemunho, partiu-se de um conceito operacional de testemunho como o relato proveniente de experiências e situações vividas, presenciadas ou ouvidas por sobreviventes e por pessoas que foram afetadas diretamente ou tiveram algum envolvimento com o acontecimento. A partir dessa delimitação, dividimos as testemunhas em três grupos (sobreviventes; pais, familiares, amigos e professores das vítimas; voluntários e moradores sensibilizados pela tragédia) e observamos os conteúdos mais recorrentes em cada um deles.

Entre os sobreviventes, notamos que os testemunhos versaram, principalmente, sobre o início do fogo, a fuga dos frequentadores (caos, tumulto e desespero), a estrutura interna da casa noturna (existência de barras de ferro, o tamanho da porta de saída, a ausência de equipamentos de sinalização), a superlotação e o resgate dos corpos realizados por sobreviventes.

Já no grupo dos pais, familiares, amigos e professores, não há dúvidas de que a característica principal é a expressão dos sentimentos de dor e perplexidade por parte de quem havia perdido parentes no incêndio. Foram os depoimentos mais desoladores ao mostrarem a ruptura entre o passado feliz ao lado do filho e o presente trágico, assim como os mais revoltados com a falta de fiscalização que poderia ter evitado a tragédia.

O grupo 3, que abrange os testemunhos dos voluntários e moradores sensibilizados pela tragédia, é o que apresenta os depoimentos menos dramáticos, porém demonstram a comoção gerada na cidade. Invariavelmente, os depoimentos falam sobre a dor dos pais e familiares e a solidariedade a eles, associada a um sentimento de gratidão por não ter perdido ninguém no incêndio.

Após essa tipologia, examinamos cada depoimento a partir dos parâmetros sistematizados por Charaudeau (2010) sobre as formas de provar a verdade e de conferir emoção ao discurso.

Como os testemunhos participam da cobertura? A designação, a reconstituição, a elucidação nos testemunhos

Contrariando o senso comum de associar as coberturas de tragédia ao sensacionalismo e à exploração do drama humano, na cobertura analisada, verificamos que $66,6 \%$ das fontes testemunhais cumpriram um papel, primordialmente, de confirmar a ocorrência do acontecimento. O resultado vai ao encontro da vocação do jornalismo de informar e do pressuposto de que as fontes são convocadas para provar a verdade do relato.

Também corrobora para esse entendimento os questionamentos feitos pelos jornalistas às fontes, os quais tiveram o objetivo primeiro de entender- a partir do depoimento das testemunhas- o que havia propiciado a tragédia, e não especificamente, de emocionar o público. Entre as perguntas realizadas pelos jornalistas, $73,2 \%$ fizeram menção a questões pontuais, como o posicionamento do sobrevivente na boate quando o fogo começou, o que deu origem às chamas, a existência de saída de emergência e a barreira que teria sido feita pelos seguranças para impedir a saída dos frequentadores sem o pagamento da comanda de consumo.

Entre todas as categorias discursivas, a designação é a mais recorrente, sendo observada em $58,4 \%$ das sequências. Essa predominância pode ser explicada a partir do seu próprio conceito, que visa à construção do efeito de transparência e autenticidade, sem a necessidade de in- 
terligação e contextualização dos fatos. Observamos que o procedimento contribuiu, primeiramente, com o apontamento de indícios iniciais. Ao ser questionada, ainda na manhã de domingo (27/01/2013), sobre "o que aconteceu exatamente", uma sobrevivente respondeu: "um amigo nosso viu que tava incendiando em cima dos cantores e daí a gente começou a sair". Apesar de não dizer, exatamente, onde começou o incêndio (apenas "em cima dos cantores"), ela confirma a ocorrência do incêndio ${ }^{3}$. Quando é indagada sobre a suspeita de as chamas terem iniciado no palco, esclarece: "foi muito fogo, foi em cima, acho que pegou no teto" (SD4). Observamos que a indicação do local ("foi em cima, acho que pegou no teto") já aparece mais delineada, assim como a extensão das chamas (" $f o i$ muito fogo").

\section{Os testemunhos}

\section{também fornecem}

\section{respostas bastante definitivas}

Além de designarem indícios iniciais, os testemunhos também fornecem respostas bastante definitivas. Verificamos essa situação quando os apresentadores do Esporte Espetacular (27/01/2013) mostraram uma fotografia do palco da boate antes da tragédia e pediram para uma sobrevivente (entrevistada por telefone) confirmar onde o fogo iniciou. A resposta não deixa dúvidas: "à esquerda do palco, em cima do teto".

Ainda por meio da designação, percebemos a contribuição dos testemunhos para o esclarecimento de questões polêmicas, como a barreira que teria sido feita por seguranças para impedir a saída sem o pagamento da comanda de consumo, conforme afirmou um sobrevivente: "alguns estavam fazendo barreira e di- zendo que a gente só ia sair se pagasse". "Só liberaram a gente quando viram que o fogo vinha se alastrando pelo teto e caindo todo aquele fogo por cima das pessoas". Como pode ser visto, os testemunhos esclarecem o que até então era encarado como uma possibilidade, transformando-se em representações da verdade.

Já o procedimento da reconstituição foi identificado em apenas $8,2 \%$ das sequências discursivas, no nosso entendimento, porque nos momentos iniciais da cobertura é difícil ter as informações necessárias para o encadeamento das ações. A título de ilustração, cita-se o testemunho de uma jovem sobre o que ocorreu após a faísca do artefato pirotécnico atingir o teto: "Eles [integrantes da banda] tentaram apagar, pegaram um extintor $e$ não funcionou. Em segundos, começou o teto todo pegando fogo". Ao afirmar que "tentaram apagar", "pegaram um extintor" e "em segundos, começou o teto todo pegando fogo", a sobrevivente hierarquiza uma sequência de ações, possibilitando a reconstituição do início do incêndio. Por mais que a informação pareça inicial demais, naquele momento (manhã de 27/01/2013) qualquer relação articulada pelos sobreviventes poderia ser relevante para os jornalistas.

Ainda observamos que quanto mais detalhes informados, maior o potencial reconstituidor do testemunho, como evidencia o depoimento de outro sobrevivente transmitido na tarde do dia 27/01/2013:

O vocalista da banda resolveu colocar um daqueles... aquela coisa, que não é permitida em estádio, na mão. E no momento que acendeu, começou a agitar, e a pular, e ergueu demais o braço, e é baixinho o teto. E logo em seguida, pegou fogo no forro, na forração do telhado, da cobertura ali.

Notamos que a sobrevivente reconstrói cronologicamente os fatos que culminaram no incêndio, propiciando o efeito de verossimilhança característico da reconstituição. Também identifica-
${ }^{3}$ Muitos frequentadores afirmaram que saíram da boate porque pensaram se tratar de uma briga. Por isso, a confirmação de que houve fogo não pode ser interpretada como óbvia naquele momento da cobertura. 
mos esse procedimento em relação à saída dos frequentadores da casa noturna.

Quando ela [minha amiga] gritou, eu olhei pro palco e já tava pegando fogo no palco. Mas foi muito rápido. E as pessoas começaram a se desesperar e a sair correndo, só que na porta... a dificuldade tava bem grande pra sair porque tinha umas barras de ferro fixas no chão, muita gente acabou ficando presa.

O depoimento evidencia a recomposição do momento da fuga e do ambiente interno da boate. Esse último aspecto é ainda mais notório no testemunho de outro sobrevivente:

Quando tu entra na boate (...) é como se fosse um corredor, tem os caixas que fazem o atendimento do pessoal quando entra. Aí tem uma segunda porta que dá acesso à boate e aquela porta fica fechada e eles não têm como ver o que acontece lá dentro.

Após essas análises, concluímos que, por meio da reconstituição, os testemunhos colaboraram para o esclarecimento de três questões: o início do fogo, a fuga da boate e a estrutura da casa noturna.

Por outro lado, não identificamos nenhuma contribuição ao discurso jornalístico por meio do procedimento da elucidação. No nosso entendimento, isso ocorreu porque não cabe às testemunhas elucidarem o caso, pois tendo em vista que se manifestam a partir de uma experiência, não têm capacidade de fornecerem certezas absolutas. Ainda que em outros campos (como o jurídico) essa possibilidade exista, compreendemos que no jornalismo o testemunho não se constitui em um relato acabado, estando sempre inserido em uma rede explicativa maior, no qual fazem parte outras fontes. Dessa forma, concluímos que o testemunho pode designar elementos, reconstituir situações, dar luz a questões polêmicas, mas dificilmente elucidar totalmente os fatos.

Após a discussão dessas três formas de provar a verdade, parte-se para o efeito patêmico. Apesar de não estar incluí- do na sistematização entre as provas da verdade, o efeito mantém estreitas relações com a questão da veracidade.

\section{O efeito patêmico nos testemunhos}

Uma rápida observação das sequências classificadas como efeito patêmico $(33,3 \%)$ pode dar margem ao entendimento de que todas remetem apenas ao fazer sentir. Porém, com um olhar mais atento, também se encontram elementos de uma visada de informação que ilustram outros aspectos para a reconstrução da tragédia.

Um dos casos mais recorrentes é a patemização cumprindo o papel de demonstrar as emoções de quem estava dentro da boate, como evidenciam as sequências "E daí eu vi tudo, foi horrível, horrivel", "Foi um terror, foi horrivel ver aquelas pessoas caindo, morrendo" e "Mas tá complicado, parece que o terror não vai passar". Todas demonstram mais sentimentos do que fatos, porém, é importante salientar que uma cobertura de tragédia não pode prescindir dos aspectos humanos. Logo, esses depoimentos são necessários para compor o discurso. Além disso, também podem ser interpretados como uma prova de verdade em relação à dificuldade de escapar da casa noturna.

\section{O efeito patêmico colabora para dar a dimensão da tragédia}

Ademais, percebemos que o efeito patêmico colabora para dar a dimensão da tragédia. Na sequência "foi uma coisa tão grande, tão grande que [a ficha] acaba não caindo", a irmã de uma jovem morta no incêndio expõe tanto o aspecto catas- 
trófico do fato ("tão grande, tão grande"), como a incredulidade dos familiares (" $a$ ficha] acaba não caindo").

As sequências patêmicas ainda retrataram a angústia dos familiares frente à falta de informações sobre a identidade dos mortos e a localização dos sobreviventes (levados para diferentes hospitais e pronto-atendimentos). Um exemplo disso é o depoimento de uma mãe que perdeu dois filhos na tragédia, um ainda na noite do incêndio e o outro depois de dias internado no hospital.

Mas na verdade, ele tava indo pra lá [para um hospital de Porto Alegre] e eu não podia ir porque até aquela hora eu não sabia nada do Davis, eu não tinha notícia do Davis, os hospitais não tinham notícia, a prefeitura aqui, aqui, no CDM [Centro Desportivo Municipal $\left.{ }^{4}\right]$.

Nesse caso, o sentimento de incerteza e de indignação é explícito quando a mãe relata que não pôde acompanhar a remoção de um filho para Porto Alegre, porque ainda não havia encontrado o outro. A revolta com a tragédia também é retratada de forma mais intensa no testemunho: "Eu achei um absurdo, as pessoas morrendo e ele pensando no dinheiro. Eu achei um absurdo isso", em que uma sobrevivente repudia ("as pessoas morrendo e eles pensando em dinheiro"; "um absurdo") a postura dos seguranças que, inicialmente, teriam impedido a saída dos frequentadores.

Ainda observamos que o efeito patêmico ainda ilustra o impacto da tragédia em pessoas não atingidas diretamente pelo incêndio. Por um lado, tem-se a tristeza sentida ("E parece que o clima se torna mais triste ainda quando a gente vê pessoas que saem desse Centro [Desportivo Municipal] que identificaram um filho, uma filha, até mesmo colegas que estão lá"); por outro, o sentimento de gratidão por não terem perdido ninguém ("Meus filhos, graças a Deus, a minha filha ia na boate e não foi. Então eu só tenho a agradecer a Deus"); e ainda a solidariedade às famílias dos mortos ("É uma coisa tão simples, oferecer um copo d'água, um alimento, mas parece uma coisa tão grande pra eles, que não tem explicação").

É por todos esses exemplos que a patemização não pode ser associada apenas à captação, uma vez que não demonstram apenas emoções, mas outros aspectos da tragédia. Dessa forma, conseguimos observar, na prática, a característica que define o procedimento: emocionar e informar ao mesmo tempo.

Dessa forma, compreendemos o efeito patêmico como indissociável da cobertura de tragédias, mesmo que predominem as incidências das provas de verdade (66,6\%). Sugerimos que a patemização esteja imbricada até mesmo nesses enunciados, entendidos supostamente como mais objetivos, como em "Todo mundo ajudando os que tavam saindo de lá... as pessoas carregando pelos braços, pelas pernas". A sequência foi classificada como designação, pois apresenta elementos que conferem efeito de verdade ao fornecerem provas de que o fato realmente ocorreu (pessoas carregadas, pretas de fumaça, queimadas e mortas), entretanto, identificamos também um certo teor patêmico. $\mathrm{Na}$ explanação do modo como as pessoas eram carregadas ("pelos braços e pernas"), transmite-se a ideia da incapacidade de elas deixarem o local por conta própria. Dessa forma, pode-se imaginar o desespero de quem estava tentando salvar as vítimas ("todo mundo ajudando os que tavam saindo de lá") a ponto de retirá-las de qualquer maneira ("pelos braços e pernas"), tanto quanto a fragilidade de quem estava sendo resgatado.

Por sua vez, as sequências que reconstituem a forma como os fatos se sucederam na boate também apresentam aspectos patêmicos, com indicam os exemplos abaixo:
${ }^{4}$ O Centro Desportivo Municipal (CDM) é um complexo esportivo para onde foram levados os corpos para o processo de identificação. 
Eu vi tudo. A hora que começou, os vocalistas tentaram apagar o fogo, apavorados. Quando eles viram que não conseguiram, saiu todo mundo correndo.

As meninas, principalmente, por causa do salto alto, não conseguiam correr. Algumas tiravam o salto e caíam em caco de vidro; outras, caíam e o pessoal pisoteava.

Ao mesmo tempo em que recompõem o modo como os fatos ocorreram, as sequências também transmitem $o$ sofrimento dos sobreviventes tentando deixar o local. Os detalhes informados estabelecem não só a relação de encadeamento dos acontecimentos, mas também o efeito patêmico decorrente dos aspectos dramáticos que circundam essa reconstituição. De mesmo modo, é notória a ideia de pânico ("saiu todo mundo correndo") após a constatação de que o fogo não foi controlado pelos integrantes da banda e na descrição das meninas que tiraram o sapato de salto na esperança de correr e acabaram pisoteadas.

Nas coberturas de tragédias, os testemunhos, ainda que forneçam elementos concretos de informação (como o local do início do fogo e os obstáculos que prejudicaram a fuga), estão envoltos na emoção inerente à tragédia. Entretanto, a patemização não está atrelada apenas à emoção - e consequentemente, à captação da audiência - mas também à visada da informação. Como pode ser percebido, o transbordamento emocional característico do patêmico também acaba colaborando com o efeito de verdade do relato, de forma semelhante aos processos de designação e reconstituição.

\section{Considerações Finais}

Após essas reflexões, ressaltamos a importância dos testemunhos na co- bertura ao vivo de tragédias. Se, de certa forma, o aspecto emocional da tragédia já era pressuposto, o resultado da análise discursiva mostra a primazia das provas de verdade com incidência de $66,6 \%$. Isto é, em sua maioria, as testemunhas foram convocadas para comprovar a ocorrência do fato e não apenas para emocionar o público.

Ainda que a emoção esteja presente e seja indissociável da manifestação de quem passou por uma situação extrema, constatamos que, prioritariamente, as testemunhas contribuíram com a cobertura esclarecendo questões pontuais, como exemplifica a fala de um sobrevivente a respeito do início do fogo ("quando os vocalistas viram que começou a incendiar, eles pegaram um extintor que não funcionou e aquele fogo começou a se espalhar em segundos") e da porta de saída da boate ("era uma porta com duas folhas, mas na hora que a gente saiu só tava uma aberta").

Por outro lado, após a análise das sequências patêmicas $(33,3 \%)$, constatamos uma conexão do fazer sentir (comumente associado à patemização e, consequentemente, à visada de captação) com o fazer saber. Assim, percebemos o quanto os testemunhos restritos ao relato de emoção também podem colaborar com a visada de informação. Além de ilustrar o caráter mais humano da tragédia, a patemização também retratou a dimensão da tragédia e da incredulidade, a angústia dos familiares pela falta de informações sobre as vítimas, a revolta com o destino dos jovens e a falta de fiscalização das autoridades e a solidariedade disseminada entre os moradores da cidade. Como conseguimos observar, a patemização vai bem além da tarefa de emocionar numa cobertura de tragédia.

De outro modo, verificamos que as sequências identificadas como provas de verdade e, portanto, ligadas ao fazer saber, também parecem remeter ao fazer sentir. 
Quando o sobrevivente afirma que viu algumas pessoas caindo no chão e sendo pisoteadas e, por fim, mortas em macas, é notório o sentimento de desespero presente na declaração. Ainda que os elementos de marcação de realidade sejam claramente identificados e remetam à visada do fazer saber, não se pode dizer que o enunciado atenda apenas à visada de informação. Nesse contexto, o fazer sentir que, usualmente, ocupa uma posição secundária no jornalismo, passa a ter maior relevância, aproximando-se do fazer saber.

Independentemente do procedimento discursivo identificado, a patemização parece inerente ao acontecimento trágico. No entanto, a finalidade atribuída ao testemunho é um dos impor- tantes fatores que vai permitir ou não a espetacularização do drama humano. Como comprovamos em nossa pesquisa, os testemunhos produzem o efeito não só da emoção necessária para ilustrar o sofrimento, mas a possibilidade de provas de verdade que podem esclarecer os aspectos iniciais do fato e, até mesmo, ajudar no apontamento de causas, motivos e consequências da tragédia - ainda que não possam fornecer certezas absolutas. Nesse sentido, compartilhamos do entendimento de Amaral (2011, p.80) de que não são os elementos trágicos que provocam o sensacionalismo, mas a falta de contextualização e a ênfase nesses aspectos por muito tempo ao longo da cobertura.

\section{Referências}

AGAMBEN, Giorgio. O que resta de Auschwitz: o arquivo e a testemunha (Homo Saccer III). São Paulo: Boitempo, 2008.

AMARAL, Márcia Franz. A representação dos testemunhos no discurso das catástrofes ambientais: de sujeitos sociais a sujeitos discursivos. In: Revista Contracampo, v.15, n.3, set. 2013. Nitéroi: Contracampo, 2013a, p.182-190.

Os testemunhos de catástrofes nas revistas brasileiras: do medo individual à patemização midiática. In: Revista Contracampo, v.26, n.1, abr. 2013, Niterói: Contracampo, 2013b, p.71-86.

. O enquadramento nas catástrofes: da interpelação da experiência ao relato da emoção. In: Revista Contracampo, n.22, fev. 2011, Niterói: Contracampo, 2011, p.65-82.

BOURDIEU, Pierre. Sobre a televisão. Rio de Janeiro: Jorge Zahar Ed.,1997.

CHARAUDEAU, Patrick. Discurso das Mídias. São Paulo: Contexto, 2010a.

. Emoção. In: CHARAUDEAU, Patrick.; MAINGUENEAU, Dominique. Dicionário de análise do discurso. São Paulo: Contexto, 2014.

LEAL, Bruno Souza; ANTUNES, Elton. O testemunho midiático como figura de historicidade: implicações teóricometodológicas. 2015. Disponível em $<$ http://www. compos.org.br/biblioteca/www.compos.org.br_template_template2_2887.pdf> LOZANO ASCENCIO, Carlos. Aportaciones para uma historia del acontecer 
catastrófico. 2004. Disponível em <http:www.ubi.bocc.pt>. Acesso em: 15 jun. 2015

PENNA, João Camillo. Este corpo, esta dor, esta fome: notas sobre o testemunho hispano-americano. In: SELIGMANN-SILVA, Márcio (Org.). História, memória, literatura: o testemunho na era das catástrofes. Campinas: Ed. Unicamp, 2003.

RICOEUR, Paul. A memória, a história e o esquecimento. Campinas, SP: Editora Unicamp, 2007

SARLO, Beatriz. Tiempo Pasado: cultura de la memoria y giro subjetivo, uma discusión. Buenos Aires: Ed. Siglo XXI, 2005.

SELLIGMAN-SILVA, Márcio. História, memória, literatura: o testemunho na era das catástrofes. Campinas: Ed. Unicamp, 2003. 